\title{
DESEMPENHOAGRONÔMICO DE TRÊS CULTIVARES DE SOJA EM DIFERENTES ÉPOCAS DE SEMEADURA EM DUAS SAFRAS
}

\author{
Agronomic performance of three soybean cultivars at different sowing times in two agriculture years
}

\author{
Marcibela Stülp ${ }^{1}$,Alessandro de Lucca e Braccini² ${ }^{2}$ Leandro Paiola Albrecht ${ }^{3}$, \\ Marizangela Rizzatti Ávila ${ }^{4}$, Carlos Alberto Scapim², Ivan Schuster ${ }^{5}$
}

\begin{abstract}
RESUMO
O cultivo da soja, com cultivares precoces, em semeadura antecipada, é uma prática comum no oeste do Estado do Paraná, visando à safrinha do milho, no entanto, pouca pesquisa é relatada sobre esse fato. Portanto, neste trabalho,objetivou-se avaliar a influência da antecipação da semeadura da soja, no desempenho agronômico de três cultivares precoces de soja, semeadas em diferentes épocas, em dois anos agrícolas. Para tanto, foram instalados ensaios de competição na unidade da COODETEC, em Palotina - Paraná. O delineamento utilizado foi o em blocos casualizados, com quatro repetições, conduzido em dois anos agrícolas (2003/2004 e 2004/2005), com três cultivares precoces de soja (CD 202, CD 215 e CD 216), semeadas em cinco épocas (15/09, 30/ 09,15/10,30/10 e 15/11). As variáveis avaliadas foram: altura de inserção de primeira vagem, altura de planta, número de vagens e produtividade. Os dados coletados foram submetidos à análise de variância conjunta e realizados os desdobramentos das interações, quando necessário. Constatou-se que: a época preferencial de semeadura foi desfavorável à produção de grãos, especialmente no segundo ano agrícola; a maior produtividade de sementes para as três cultivares de soja foi obtida na semeadura realizada no mês de outubro; a antecipação na semeadura pode ser uma alternativa viável para a região oeste do Estado do Paraná.
\end{abstract}

Temos para indexação: Glycine max, semeadura antecipada, rendimento.

\section{ABSTRACT}

Growing soybean by using early maturing soybean cultivars in anticipated sowing has been a common practice in the west of Paraná State aiming at the safrinha corn (fall cropping), however, there has not been enough research reported about this fact. Therefore, the objective of this study was to evaluate the influence of sowing anticipation of three early maturing soybean cultivars during two agriculture years. For this purpose, competition experiments were installed at COODETEC, in Palotina, Paraná State. A randomized complete block design with four replications was carried out within two agriculture years (2003/2004 and 2004/2005) by using three early maturing soybean cultivars (CD 202, CD 215, and CD 216) sowed on five different days (09/15, 09/30, 10/15, 10/ 30 , and 11/15). Data were collected and submitted to variance analysis and the interaction design was accomplished whenever necessary. It was verified that the preferable period for sowing was unfavorable to the seed production, especially in the second agriculture year. The highest seed yield for the three soybean cultivars was obtained from the sowing accomplished in October. Potentially, sowing anticipation might be a viable alternative to the west region of Paraná State.

Index terms: Glycine max, anticipated sowing, production.

(Recebido em 1 de agosto de 2008 e aprovado em 14 de abril de 2009)

\section{INTRODUÇÃO}

A cultura da soja [Glycine max (L.) Merrill] está sujeita, ao longo de seu ciclo, a estresses causados pelas necessidades hídricas, térmicas e fotoperiódicas que resultam na redução da produtividade e da qualidade do produto (Câmara, 1991; Bonato et al., 1998; Embrapa, 2006). $\mathrm{E}$, provavelmente, nenhuma prática cultural isolada é mais importante para a soja do que a época de semeadura (Peixoto et al., 2000). Essa prática é a variável que produz maior impacto sobre a produção da soja, afetando, também, de modo acentuado, a arquitetura e o desenvolvimento da planta (Nakagawa et al., 1983).

As características quantitativas como componentes do rendimento (número de vagens por planta, número de grãos por vagem e massa dos grãos), altura de planta, duração do ciclo e produtividade, são as mais importantes na escolha das cultivares para cultivo sendo as mais influenciadas pelo manejo (Peixoto et al., 2000). Semeadas em diferentes épocas, as cultivares expressam suas

\footnotetext{
${ }^{1}$ Eng. Agrônoma, M.Sc., Profa ${ }^{\mathrm{a}}$. Assistente do Depto. de Agronomia, Universidade Estadual de Maringá (UEM), Av. Colombo, 5790, Maringá, PR, CEP 87020-900, Maringá, PR - marcibela@terra.com.br

²Eng. Agrônomo, Dr., Prof. Associado do Depto. de Agronomia, UEM, Maringá, PR; Bolsista do CNPq - albraccini@uol.com.br; cascapim@uem.br ${ }^{3}$ Eng. Agrônomo, M.Sc., Prof. Assistente do Depto. de Agronomia, UEM, Maringá, PR - Ipalbrecht@yahoo.com.br

${ }^{4}$ Eng. Agrônoma, Dra-., Profa ${ }^{\text {a }}$. Adjunta do Depto. de Agronomia, UEM, Maringá, PR - marizangela_rizzatti@hotmail.com

${ }^{5}$ Eng. Agrônomo, Dr., Pesquisador da Cooperativa Central de Pesquisa Agrícola (COODETEC), BR 467, Km 98, Cx. Postal 301, Cascavel, PR, CEP 85813-450 - ivan@coodetec.com.br
} 
potencialidades em relação às condições do ambiente que mudam no espaço e no tempo (Barros et al., 2003; Pelúzio et al., 2006).

A antecipação da semeadura, segundo a Embrapa (2006), é a semeadura realizada antes de 15 de outubro. Com a antecipação, pretende-se viabilizar a sucessão de culturas da soja com o "milho safrinha". Portanto, objetivou-se, no presente trabalho, avaliar o efeito da antecipação da semeadura da soja, nas características agronômicas e na produtividade de três cultivares precoces de soja, em dois anos agrícolas.

\section{MATERIALE MÉTODOS}

O presente trabalho foi conduzido nos anos agrícolas de 2003/2004 e 2004/2005, no município de Palotina, na região oeste do Paraná, pertencente à Cooperativa Central de Pesquisa Agrícola - COODETEC, em solo classificado como Latossolo Vermelho Eutroférrico.

O clima predominante na região é do tipo $\mathrm{Cfa}$, mesotérmico úmido, com chuvas abundantes no verão e inverno seco, segundo classificação de Köppen, adotada pelo IAPAR. Os dados de precipitação pluvial, temperaturas máxima e mínima diária e umidade relativa do ar, foram coletados diariamente nos dois anos agrícolas (Figura 1) (IAPAR, 2006).

Foram instalados ensaios de competição com três cultivares precoces de soja (CD 202, CD 215 e CD 216). A semeadura da soja foi realizada em 15/09, 30/09, 15/10, 30/10 e 15/11. As parcelas foram constituídas por oito linhas de 5 metros de comprimento, espaçadas de $0,45 \mathrm{~m}$ entre si. A área útil das unidades experimentais foi de 7,2 $\mathrm{m}^{2}$ para os dois anos agrícolas. O preparo do solo, a adubação e as demais práticas culturais foram implementadas segundo preconizações do sistema de produção da região (Embrapa, 2003).

Para a determinação da altura de planta e inserção das primeiras vagens na cultura da soja, foram avaliadas dez plantas ao acaso na área útil das parcelas. $\mathrm{O}$ número de vagens por planta foi avaliado por ocasião da maturação, estádio $\mathrm{R}_{8}$ de desenvolvimento, a partir de uma amostra de 10 plantas por parcela. Partindo-se do rendimento de sementes, foram calculadas as produtividades em kg ha-1. Os dados de produtividade foram corrigidos para $13 \%$ de umidade. $\mathrm{O}$ grau de umidade das sementes foi avaliado por meio do método de estufa a $105^{\circ} \mathrm{C}$ por 24 horas (Brasil, 1992).

$\mathrm{O}$ delineamento experimental foi em blocos casualizados com quatro repetições de campo, sendo que cada época de semeadura foi constituída de ensaio individual de competição de cultivares. Posteriormente, os dados coletados foram submetidos à análise de variância conjunta $\mathrm{e}$ verificou-se a semelhança dos quadrados médios pelo Teste de Hartley (Ramalho et al., 2000). A análise conjunta dos dados foi realizada para as diferentes épocas de semeadura (Banzatto \& Kronka, 2008). Nesse experimento, foram adotados efeitos fixos. Foram calculadas as esperanças do quadrado médio, conforme modelo biométrico adotado e, segundo pressupostos de Cruz et al. (2004). Independente da significância pelo teste $\mathrm{F}(P<0,05)$, na interação de segunda ordem, prosseguiram-se os desdobramentos necessários.

\section{RESULTADOS E DISCUSSÃO}

Em relação as variáveis resposta, altura de inserção da primeira vagem e altura de planta (Tabela 1), de modo geral, o primeiro ano agrícola (2003/2004) obteve resultados superiores ao segundo (2004/2005). Comparando-se altura de inserção e altura de planta, para as cultivares dentro de cada ano agrícola, observam-se também algumas diferenças significativas entre as cultivares dentro das épocas (Tabela 1), demonstrando a variabilidade existente entre os genótipos em função do meio. Esses dados vêm a corroborar com, Câmara (1991) e Pelúzio et al. (2006), os quais observaram que a época de semeadura, além do rendimento, afeta a arquitetura e o desenvolvimento das
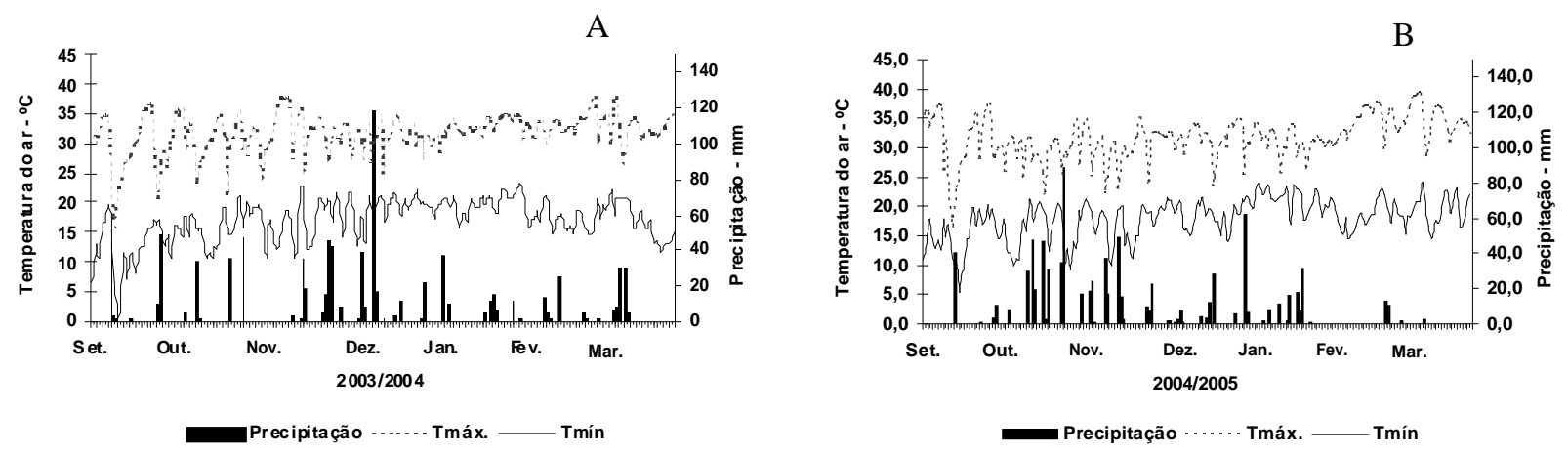

Figura 1 - Temperaturas máxima e mínima e precipitação pluvial, em Palotina, Estado do Paraná, de setembro a março do ano agrícola 2003/2004 (A) e 2004/2005 (B). 
plantas, dificultando a colheita mecânica em virtude das reduções na altura da planta e altura de inserção de vagem.

As maiores alturas de planta foram obtidas pela cultivar CD 216, para algumas épocas de semeadura, nas duas safras avaliados, encontram-se de acordo com as características da cultivar, pois sendo dotada de hábito de crescimento indeterminado (COODETEC, 2005), a mesma continua crescendo após o florescimento.
O comportamento da variável altura de inserção de primeira vagem, em função das épocas de semeadura, para cada cultivar de soja, foi analisado por regressão (Figura 2). A variável altura de inserção para a cultivar CD 202 apresentou comportamento cúbico com relação às épocas de semeadura no primeiro ano agrícola, em que a maior altura de inserção de vagem $(13,91 \mathrm{~cm})$ foi obtida aos 12 dias a partir de 15/09.

Tabela 1 - Resultados médios da altura de inserção da primeira vagem e altura de planta, em centímetros, obtidos de três cultivares de soja, produzidas em cinco épocas de semeadura, nas safras 2003/2004 e 2004/2005, em Palotina - PR.

\begin{tabular}{|c|c|c|c|c|c|c|}
\hline \multirow{3}{*}{ Cultivar $^{1}$} & \multirow{2}{*}{\multicolumn{2}{|c|}{$\begin{array}{c}\text { Altura de inserção da primeira } \\
\text { vagem }\end{array}$}} & \multicolumn{4}{|c|}{ Altura de planta } \\
\hline & & & \multirow[t]{2}{*}{ Média } & \multicolumn{2}{|c|}{ Ano agrícola } & \multirow[t]{2}{*}{ Média } \\
\hline & $2003 / 04$ & $2004 / 05$ & & $2003 / 04$ & $2004 / 05$ & \\
\hline \multicolumn{7}{|c|}{$\begin{array}{c}\text { Época de semeadura } \\
15 / 09 \\
\end{array}$} \\
\hline CD 202 & $11,75 \mathrm{Aa}$ & $9,25 \mathrm{Ab}$ & 10,50 & $56,75 \mathrm{Ba}$ & $45,00 \mathrm{Bb}$ & 50,88 \\
\hline CD 215 & 9,00 Aa & $6,00 \mathrm{Bb}$ & 7,50 & $73,50 \mathrm{Aa}$ & $35,25 \mathrm{Bb}$ & 54,38 \\
\hline CD 216 & $10,50 \mathrm{Aa}$ & $6,00 \mathrm{Bb}$ & 8,25 & $64,00 \mathrm{ABa}$ & $60,25 \mathrm{Aa}$ & 62,13 \\
\hline Média & 10,41 & 7,08 & & 64,75 & 46,83 & \\
\hline \multicolumn{7}{|c|}{$30 / 09$} \\
\hline CD 202 & $12,75 \mathrm{Aa}$ & $8,00 \mathrm{Ab}$ & 10,38 & $65,50 \mathrm{Ba}$ & $72,00 \mathrm{Aa}$ & 68,75 \\
\hline CD 215 & $11,00 \mathrm{Aa}$ & $9,00 \mathrm{Aa}$ & 10,00 & $61,75 \mathrm{Ba}$ & $57,00 \mathrm{Ba}$ & 59,38 \\
\hline CD 216 & $15,50 \mathrm{Aa}$ & $9,50 \mathrm{Ab}$ & 12,50 & $75,75 \mathrm{Aa}$ & $66,00 \mathrm{ABa}$ & 70,88 \\
\hline Média & 13,08 & 8,83 & & 67,67 & 65,00 & \\
\hline \multicolumn{7}{|c|}{$15 / 10$} \\
\hline CD 202 & $12,50 \mathrm{Ba}$ & $12,25 \mathrm{Aa}$ & 12,38 & $74,25 \mathrm{Bb}$ & $89,25 \mathrm{Aa}$ & 81,75 \\
\hline CD 215 & $29,00 \mathrm{Aa}$ & $10,50 \mathrm{ABb}$ & 19,75 & $69,25 \mathrm{Ba}$ & $70,50 \mathrm{Ba}$ & 69,88 \\
\hline CD 216 & $29,00 \mathrm{Aa}$ & $8,50 \mathrm{Bb}$ & 18,75 & $99,50 \mathrm{Aa}$ & $74,50 \mathrm{Bb}$ & 87,00 \\
\hline Média & 23,50 & 10,42 & & 81,00 & 78,08 & \\
\hline \multicolumn{7}{|c|}{$30 / 10$} \\
\hline CD 202 & $8,25 \mathrm{Ab}$ & $11,75 \mathrm{Aa}$ & 10,00 & $105,50 \mathrm{Aa}$ & $78,75 \mathrm{Ab}$ & 92,13 \\
\hline CD 215 & $8,25 \mathrm{Ab}$ & $11,50 \mathrm{Aa}$ & 9,88 & $101,75 \mathrm{Aa}$ & $70,00 \mathrm{Ab}$ & 85,88 \\
\hline CD 216 & 7,75 Aa & $9,75 \mathrm{Aa}$ & 8,75 & $109,50 \mathrm{Aa}$ & $79,75 \mathrm{Ab}$ & 94,63 \\
\hline Média & 8,08 & 11,00 & & 105,58 & 76,16 & \\
\hline \multicolumn{7}{|c|}{$15 / 11$} \\
\hline CD 202 & $14,75 \mathrm{Aa}$ & $10,25 \mathrm{Ab}$ & 12,50 & $102,25 \mathrm{Aa}$ & $62,75 \mathrm{Bb}$ & 82,50 \\
\hline CD 215 & $16,50 \mathrm{Aa}$ & $9,25 \mathrm{Ab}$ & 12,88 & $100,50 \mathrm{Aa}$ & $57,00 \mathrm{Bb}$ & 78,75 \\
\hline CD 216 & 7,75 $\mathrm{Ba}$ & $9,75 \mathrm{Aa}$ & 8,75 & $65,50 \mathrm{Bb}$ & $90,75 \mathrm{Aa}$ & 78,13 \\
\hline Média & 13,00 & 9,75 & & 89,41 & 70,16 & \\
\hline C.V.(\%) & \multicolumn{2}{|c|}{14,79} & \multicolumn{4}{|c|}{9,58} \\
\hline
\end{tabular}

${ }^{1}$ Médias seguidas de mesma letra maiúscula, em cada coluna, não diferem entre si pelo teste de Newman Keuls, a 5\% de probabilidade.

${ }^{2}$ Médias seguidas de mesma letra minúscula, em cada linha, não diferem entre si pelo teste $\mathrm{F}$, a $5 \%$ de probabilidade. 

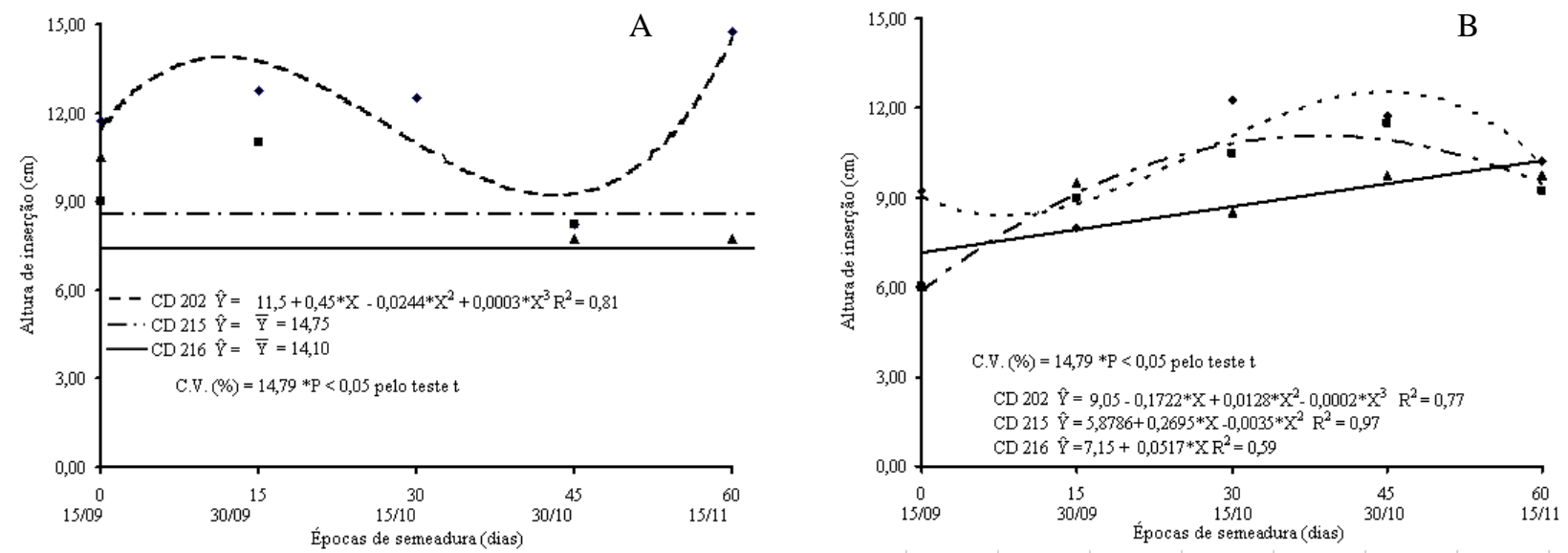

Figura 2 - Regressão polinomial para a altura de inserção de vagem de três cultivares de soja, em cinco épocas de semeadura, nos anos agrícolas de 2003/2004 (A) e 2004/2005 (B), em Palotina - PR.

No segundo ano agrícola (2004/2005), para a cultivar CD 215, o comportamento da variável altura de inserção de primeira vagem foi quadrático com ponto de máximo aos 39 dias após 15/09; no entanto, na cultivar CD 216, a variável apresentou tendência linear crescente. A cultivar CD 202, por sua vez, apresentou comportamento cúbico para a variável altura de inserção de vagem com o retardamento da época de semeadura, com altura máxima aos 35 dias.

Analisando a Figura 3, observou-se que, para o primeiro ano agrícola (2003/2004), a cultivar CD 202 apresentou comportamento linear crescente, em que as plantas cresceram $0,873 \mathrm{~cm}$ por dia. A cultivar CD 215 apresentou comportamento cúbico, com máxima altura de planta de 105,6 cm obtida aos 54 dias após 15/09. Na cultivar CD 216, dentro desse mesmo ano, observou-se tendência quadrática, em que a maior altura de planta foi obtida aos 33 dias após 15/09, alcançando 101,1 cm de altura (Figura 3A).

No segundo ano agrícola (2004/2005), a variável altura de planta apresentou comportamento quadrático para as cultivares CD 202 e CD 215 com pontos de máximo obtidos aos $34(86,36 \mathrm{~cm})$ e $37(71,23 \mathrm{~cm})$ dias após 15/09, respectivamente. Para a cultivar CD 216, por sua vez, a variável altura de planta apresentou comportamento linear crescente, com incremento diário na altura de $0,4983 \mathrm{~cm}$ ao dia de atraso na semeadura (Figura 3B).

A menor altura de planta, verificadas na primeira $(15 / 09)$ e quinta (15/11) épocas, como especialmente observada no caso da cultivar CD 215 (na safra 2004/05) vem a sugerir que os plantios mais tardios e mais precoces resultam em plantas com menor altura, quando comparados com plantios realizados na época recomendada para a cultura da soja. O que foi também constatado por
Melhorança \& Mesquita (1982), com trabalho realizado em Dourados - MS.

Em relação à característica número de vagens por planta (Tabela 2), com algumas exceções, foi superior no segundo ano agrícola (2004/2005); explicando, deste modo, baixos rendimento, para 2003/04, na última época de semeadura. No segundo ano (2004/2005), a cultivar CD 216 apresentou o menor valor para está característica, em praticamente todas as épocas de semeadura, porém, tais resultados não implicaram em baixa produtividade de grãos. Por outro lado, a cultivar CD 202 foi a que apresentou o melhor desempenho no número de vagens por planta na segunda (30/09) e na quarta (30/10) épocas de semeadura.

Quanto à produtividade de grãos ( $\mathrm{em} \mathrm{kg} \mathrm{ha}^{-1}$ ) (Tabela 2) na terceira época (15/10), em contraste com a primeira época, o primeiro ano foi inferior ao segundo ano agrícola no rendimento de sementes, para a cultivar CD 202. Esse resultado foi obtido, provavelmente, em virtude do déficit hídrico sofrido por essa cultivar no segundo decêndio de dezembro do ano de 2004 (Figura 1), coincidindo com a fase inicial de enchimento de grãos. Isso se deve ao fato de que as outras duas cultivares são de ciclo mais precoce que a CD 202 (COODETEC, 2005) e, dessa forma, poderiam ter "escapado" desse período de estiagem.

Na quarta (30/10) e quinta (15/11) épocas de semeadura, o ano agrícola de 2004/2005 apresentou superioridade na produtividade de sementes, em comparação com o primeiro ano (2003/2004), para todas as cultivares em estudo (Tabela 2). Apesar de 2004/2005 também ter sido um ano relativamente seco, esse apresentou chuvas melhor distribuídas ao longo do ciclo da cultura e as temperaturas mais baixas, principalmente, na fase de florescimento e enchimento de grãos (Figura 1), favorecendo o desenvolvimento da cultura e não afetando de forma tão drástica a produção, em comparação com o primeiro ano estudado (2003/2004). 

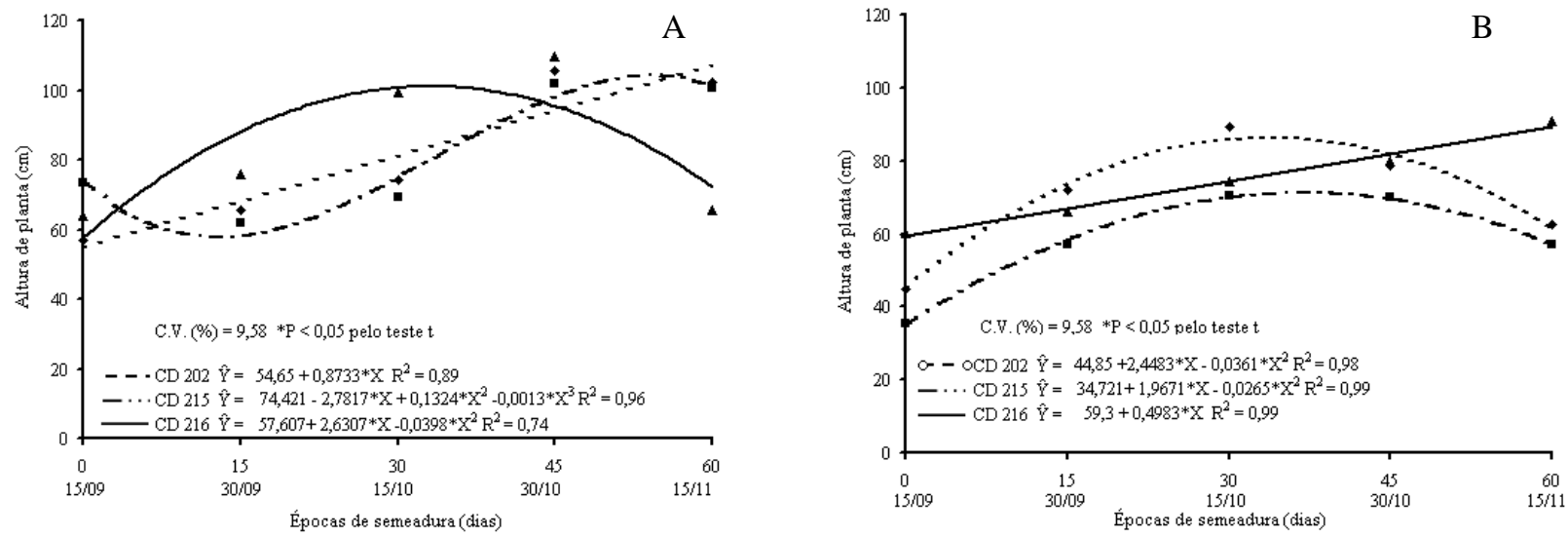

Figura 3 - Regressão polinomial para a altura de planta de três cultivares de soja, em cinco épocas de semeadura, nos anos agrícolas de 2003/2004 (A) e 2004/2005 (B), em Palotina - PR.

Dentro do primeiro ano agrícola (2003/2004), houve diferença entre as cultivares na produtividade de grãos apenas para a CD 216 na primeira época de semeadura (15/09), que foi inferior às demais cultivares, e para a CD 202 na terceira época $(15 / 10)$, que apresentou produtividade aquém da esperada, diferindo estatisticamente das cultivares CD 215 e CD 216. No segundo ano agrícola (2004/2005), a única diferença estatística apresentada para a variável produtividade, entre as cultivares, foi observada na segunda época de semeadura (30/09), em que a cultivar CD 202 apresentou rendimento médio superior a cultivar CD 216. Essa última cultivar, apesar de ser classificada como precoce, possui ciclo mais rápido que as demais cultivares estudadas (ciclo: CD 216, aproximadamente 110 dias, enquanto as outras estudadas, 115 dias - CD 215; e 118 dias - CD 202; em média), tendo apresentado produtividade menor, uma vez que deve ter sofrido mais com o déficit hídrico ocorrido na fase de florescimento e início de enchimento de grão, pois possui menor período de recuperação de um estresse (Figura 1).

O período de restrição hídrica associado a altas temperaturas, ocorrido nos meses de janeiro e fevereiro do ano de 2004 (Figura 1) e de fevereiro e março de 2005 (Figura 1), coincidindo com estádios reprodutivos da cultura, foi, provavelmente, o causador das baixas médias de produtividade observadas nos períodos de semeadura convencionais ou recomendadas pela pesquisa, ou seja, 30/10 e 15/11(Embrapa, 2006). Nesses períodos, as médias de produtividade das três cultivares avaliadas foram de apenas 1.135 e $499 \mathrm{~kg} \mathrm{ha}^{-1}$, respectivamente, para a quarta e quinta épocas de semeadura do ano agrícola de 2003/2004, e de $1.521 \mathrm{~kg}$ $\mathrm{ha}^{-1}$ para a quinta época de semeadura do segundo ano agrícola 2004/2005 (Tabela 2), pois a floração é severamente afetada pela deficiência de água no período de duas a quatro semanas que precede a diferenciação floral, mas é o período de transferência de matéria seca mais crítico para a soja, em relação a esse fator. A menor disponibilidade de água promove decréscimo da fotossíntese e abrevia o período de enchimento de grãos, com prejuízo à produção (Berlato \& Fontana, 1999; Câmara \& Heiffig, 2000; Matzenauer et al., 2003, 2005). Temperaturas elevadas, principalmente quando associadas com períodos com baixos índices pluviais durante a maturação, podem ocasionar a dita maturação "forçada", interferindo na deposição natural de carboidratos, lipídios e proteínas, já que houve redução da translocação de fotossintatos para as sementes (França Neto et al., 1993).

Foram apresentados resultados da análise de regressão em relação ao comportamento das cultivares nas cinco épocas de semeadura, para a variável número de vagens por planta (Figura 4), somente para o segundo ano agrícola (2004/2005), já que para o primeiro não houve resposta significativa. Todas as cultivares apresentaram comportamento linear decrescente com a antecipação da semeadura para a referida variável. A cultivar CD 202 diminuiu 0,64 vagem a cada dia, por planta, chegando a um mínimo aproximado de 50 vagens por planta, na antecipação para 15/09. A cultivar CD 215 decresceu 0,77 vagens por dia e por planta (com mínimo aproximado de 39 vagens por planta) e a cultivar CD 216 reduziu em 0,64 vagens (mínimo de 31 vagens). 
Tabela 2 - Resultados médios do número de vagens por planta e rendimento de grãos $\left(\mathrm{kg} \mathrm{ha}^{-1}\right)$, obtidos de três cultivares de soja, produzidas em cinco épocas de semeadura, nas safras 2003/2004 e 2004/2005, em Palotina - PR.

\begin{tabular}{|c|c|c|c|c|c|c|}
\hline \multirow{3}{*}{ Cultivar $^{1}$} & \multicolumn{2}{|c|}{ Número de vagens } & & \multicolumn{2}{|c|}{ Rendimento } & \multirow{3}{*}{ Média } \\
\hline & \multicolumn{2}{|c|}{ Ano agrícola ${ }^{2}$} & \multirow[t]{2}{*}{ Média } & \multicolumn{2}{|c|}{ Ano agrícola ${ }^{2}$} & \\
\hline & $2003 / 04$ & $2004 / 05$ & & $2003 / 04$ & $2004 / 05$ & \\
\hline \multicolumn{7}{|c|}{ Época de semeadura } \\
\hline \multicolumn{7}{|c|}{$15 / 09$} \\
\hline CD 202 & $33,00 \mathrm{Aa}$ & $41,75 \mathrm{Aa}$ & 37,38 & $3507,11 \mathrm{Aa}$ & $2410,29 \mathrm{Ab}$ & 2958,70 \\
\hline CD 215 & $36,25 \mathrm{Aa}$ & $36,25 \mathrm{Aa}$ & 36,25 & $3587,77 \mathrm{Aa}$ & $2121,24 \mathrm{Ab}$ & 2854,51 \\
\hline CD 216 & $30,25 \mathrm{Aa}$ & $36,25 \mathrm{Aa}$ & 33,25 & $2620,12 \mathrm{Ba}$ & $2082,14 \mathrm{Aa}$ & 2351,13 \\
\hline Média & 33,17 & 34,75 & & 3238,33 & 2204,56 & \\
\hline \multicolumn{7}{|c|}{$30 / 09$} \\
\hline CD 202 & $44,25 \mathrm{Ab}$ & $71,25 \mathrm{Aa}$ & 57,75 & $3792,63 \mathrm{Aa}$ & $4076,11 \mathrm{Aa}$ & 3934,37 \\
\hline CD 215 & $39,50 \mathrm{Ab}$ & $56,00 \mathrm{Ba}$ & 47,75 & $3742,81 \mathrm{Aa}$ & $3791,93 \mathrm{ABa}$ & 3767,37 \\
\hline CD 216 & $34,25 \mathrm{Aa}$ & $36,75 \mathrm{Ca}$ & 35,50 & $3692,82 \mathrm{Aa}$ & $3251,49 \mathrm{Ba}$ & 3472,16 \\
\hline Média & 39,33 & 54,67 & & 3742,75 & 3706,51 & \\
\hline \multicolumn{7}{|c|}{$15 / 10$} \\
\hline CD 202 & $39,00 \mathrm{Ab}$ & $74,00 \mathrm{Aa}$ & 56,50 & $1858,78 \mathrm{Bb}$ & $2711,38 \mathrm{Aa}$ & 2285,08 \\
\hline CD 215 & $29,00 \mathrm{Ab}$ & $67,25 \mathrm{Aa}$ & 48,13 & $2524,06 \mathrm{Aa}$ & $3109,26 \mathrm{Aa}$ & 2816,66 \\
\hline CD 216 & $29,25 \mathrm{Ab}$ & $50,25 \mathrm{Ba}$ & 46,54 & $2999,50 \mathrm{Aa}$ & $2756,53 \mathrm{Aa}$ & 2878,02 \\
\hline Média & 32,42 & 63,83 & & 2460,78 & 2859,06 & \\
\hline \multicolumn{7}{|c|}{$30 / 10$} \\
\hline CD 202 & $53,50 \mathrm{Ab}$ & $67,50 \mathrm{Aa}$ & 60,50 & $836,05 \mathrm{Ab}$ & $3283,29 \mathrm{Aa}$ & 2059,67 \\
\hline CD 215 & $43,25 \mathrm{Ab}$ & $54,25 \mathrm{Ba}$ & 48,75 & $1336,43 \mathrm{Ab}$ & $2627,88 \mathrm{Aa}$ & 1982,16 \\
\hline CD 216 & $43,50 \mathrm{Aa}$ & $50,25 \mathrm{Ba}$ & 46,88 & $1232,56 \mathrm{Ab}$ & $2706,24 \mathrm{Aa}$ & 1969,40 \\
\hline Média & 46,75 & 57,33 & & 1135,01 & 2872,47 & \\
\hline \multicolumn{7}{|c|}{$15 / 11$} \\
\hline CD 202 & $26,25 \mathrm{ABb}$ & $91,50 \mathrm{Aa}$ & 58,87 & $303,19 \mathrm{Ab}$ & $1356,65 \mathrm{Aa}$ & 829,92 \\
\hline CD 215 & $33,75 \mathrm{Ab}$ & $95,00 \mathrm{Aa}$ & 64,37 & $583,65 \mathrm{Ab}$ & $1286,80 \mathrm{Aa}$ & 935,23 \\
\hline CD 216 & $21,00 \mathrm{Bb}$ & $76,50 \mathrm{Ba}$ & 54,34 & $610,62 \mathrm{Ab}$ & $1920,89 \mathrm{Aa}$ & 1265,76 \\
\hline Média & 27,00 & 87,67 & & 499,15 & 1521,45 & \\
\hline C.V.(\%) & \multicolumn{2}{|c|}{15,53} & \multicolumn{3}{|c|}{18,39} & \\
\hline
\end{tabular}

${ }^{1}$ Médias seguidas de mesma letra maiúscula, em cada coluna, não diferem entre si pelo teste de Newman Keuls, a $5 \%$ de probabilidade.

${ }^{2}$ Médias seguidas de mesma letra minúscula, em cada linha, não diferem entre si pelo teste $\mathrm{F}$, a 5\% de probabilidade.

O comportamento da variável produtividade de sementes, em função das épocas de semeadura no ano 2003/2004 (Figura $5 \mathrm{~A})$, apresentou tendência linear decrescente para as cultivares CD 202 e CD 215, em relação à época preferencial. Pela equação linear ajustada, é possível inferir que para cada dia que se atrasa a semeadura, após 15/09, há um decréscimo de $62,429 \mathrm{~kg} \mathrm{ha}^{-1}$, na variável produtividade para a cultivar CD 202, e uma diminuição de 56,097 kg ha'-1, nesta mesma variável, para a cultivar CD 215. As tendências obtidas estão de acordo com aquelas de Mota et al. (2000, 2002) e Minuzzi et al. (2009).

Houve tendência quadrática (ponto de máximo - 14,76 dias, com produtividade de $3.197,80 \mathrm{~kg} \mathrm{ha}^{-1}$ ) na variável produtividade para a cultivar CD 216, provavelmente, em virtude da sua maior precocidade, sofrendo mais com a antecipação da semeadura, ou seja, ciclo menor, menos tempo para se restabalecer de condições adversas iniciais, como temperaturas do ar e do solo baixas, menor precipitação e insuficiência fotoperiódica (Câmara \& Heiffig, 2000; Embrapa, 2006).

A mesma situação, de comportamento quadrático, é observada no segundo ano (2004/2005) para todas as cultivares, em termos de produtividade (Figura 5B). Os pontos de máximo para a variável produtividade, foram alcançados aos 23,50 (CD 202), 23,83 (CD 215) e 26,48 (CD 216) dias após 15/09, demonstrando que a cultivar CD 216 é a menos tolerante à antecipação na semeadura. 


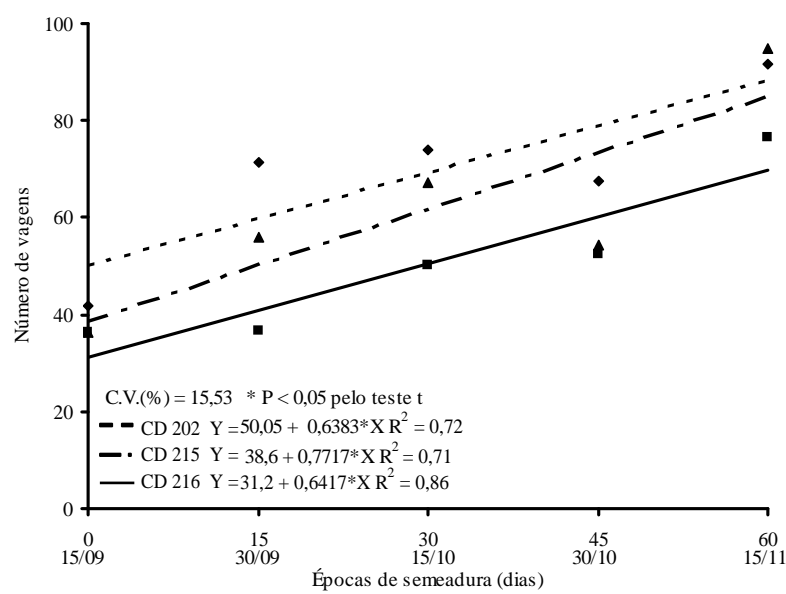

Figura 4 - Regressão polinomial para o número de vagens por planta de três cultivares de soja, em cinco épocas de semeadura, no ano agrícola de 2004/2005, em Palotina - PR.
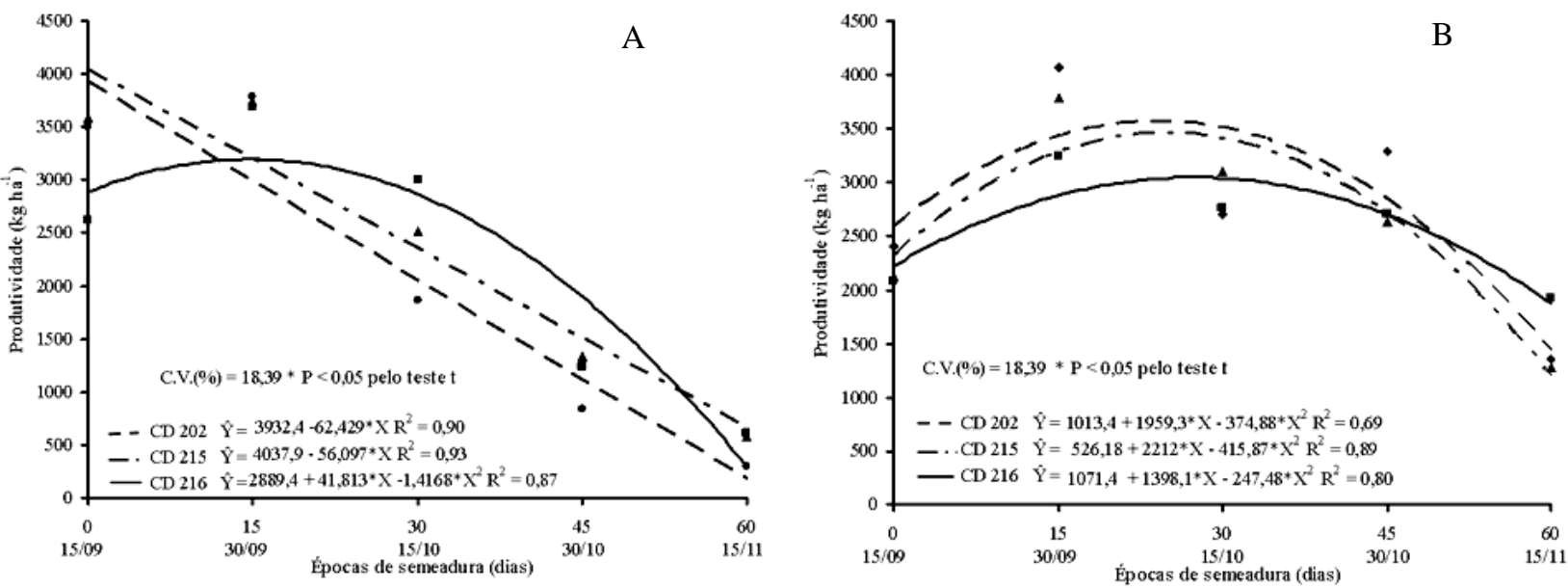

Figura 5 - Regressão polinomial para o rendimento de grãos de três cultivares de soja, em cinco épocas de semeadura, nos anos agrícolas de 2003/2004 (A) e 2004/2005 (B), em Palotina - PR.

Portanto, a época preferencial não foi a mais favorável para produção de grãos em nenhum dos dois anos em estudo, para nenhuma cultivar, em função do severo estresse por deficiência hídrica, somado a altas temperaturas. No entanto, antecipar a época de semeadura para setembro pode ser um risco à produtividade de cultivares precoces para as condições edafoclimáticas do oeste do Paraná, como, especialmente, denotado pelos resultados de 2004/05. Confirmando a afirmação de Câmara et al. (1998), em que não menos importantes são os ensaios regionais de avaliação de cultivares de soja, principalmente, quando realizados em diferentes épocas em uma mesma região.

\section{CONCLUSÕES}

Considerando a região do município de Palotina, PR, a época de semeadura, denominada preferencial (novembro) é desfavorável a produção de grãos, consistindo os maiores rendimentos de grãos, para as três cultivares de soja, a semeadura realizada no final do mês de setembro e no início do mês de outubro. 
A antecipação na semeadura da soja pode ser uma alternativa viável para a região oeste do Paraná.

\section{REFERÊNCIAS BIBLIOGRÁFICAS}

BANZATTO, D.A.; KRONKA, S.N. Experimentação agrícola. 3.ed. Jaboticabal: Funep, 2008. 237p.

BARROS, H.B.; PELUZIO, J.M.; SANTOS, M.M.; BRITO, E.L.; ALMEIDA, R.D. Efeitos das épocas de semeadura no comportamento de cultivares de soja, no sul do Estado do Tocantins. Revista Ceres, Viçosa, v.50, n.291, p.565-572, 2003.

BERLATO, M.A.; FONTANA, D.C. Variabilidade interanual da precipitação pluvial e rendimento da soja no estado do Rio Grande do Sul. Revista Brasileira de Agrometeorologia, Santa Maria, v.7, n.1, p.119-125, 1999.

BONATO, E.R.; BERTAGNOLLI, P.F.; IGNACZAK, J.C.; TRAGNAGO, J.L.; RUBIN, S.A.L. Desempenho de cultivares de soja em três épocas de semeadura, no Rio Grande do Sul. Pesquisa Agropecuária Brasileira, Brasília, v.33, n.6, p.879-884, 1998.

BRASIL. Ministério da Agricultura e Reforma Agrária. Regras para análise de sementes. Brasília, DF: DNDV/ SNAD/CLAV, 1992. 365p.

CÂMARA, G.M.S. Efeito do fotoperíodo e da temperatura no crescimento, florescimento e maturação de cultivares de soja (Glycine max $(L)$ Merrill). 1991. 266p. Tese (Doutorado)-Universidade Federal de Viçosa, Viçosa, MG, 1991.

CÂMARA, G.M.S.; HEIFFIG, L.S. Fisiologia, ambiente e rendimento da cultura da soja. In: Soja:

tecnologia da produção II. Piracicaba: ESALQ/LPV, 2000.

CÂMARA, G.M.S.; PIEDADE, S.M.S.; MONTEIRO, J.H.; GUERZONI, R.A. Desempenho vegetativo e produtivo de cultivares e linhagens de soja de ciclo precoce no município de Piracicaba - SP. Scientia Agricola, Piracicaba, v.55, n.3, p.403-412, 1998.

COODETEC. Cultivares de soja 2006. Cascavel, 2005. $54 \mathrm{p}$.

CRUZ, C.D.; REGAZZI, A.J.; CARNEIRO, P.C.S. Modelos biométricos aplicados ao melhoramento genético. 3.ed. Viçosa, MG: UFV, 2004.
EMPRESA BRASILEIRA DE PESQUISA AGROPECUÁRIA. Tecnologias de produção de soja Paraná - 2003/04. Londrina: Embrapa Soja, 2003. 218p. (Sistemas de Produção, 3).

EMPRESA BRASILEIRA DE PESQUISA AGROPECUÁRIA. Tecnologias de produção de soja Paraná - 2006. Londrina: Embrapa-CNPSo, 2006. 217p (Sistemas de Produção, 10).

FRANÇA NETO, J.B.; KRZYZANOWSKI, F.C.; HENNING, A.A.; WEST, S.H.; MIRANDA, L.C. Soybean seed quality as affected by shiveling due to heat and drought stress during seed filling. Seed Science and Technology, Zürich, v.21, n.1, p.107-116, 1993.

INSTITUTO AGRONÔMICO DO PARANÁ. Clima do Paraná. 2006. Disponível em: $\langle$ http: $/ /$ www.iapar.br/ $/ 1$. Acesso em: 12 set. 2006.

MATZENAUER, R.; BARNI, N.A.; MALUF, J.R.T. Estimativa do consumo relativo de água para a cultura da soja no Estado do Rio Grande do Sul. Ciência Rural, Santa Maria, v.33, n.6, p.1013-1019, 2003.

MATZENAUER, R.; CARGNELUTTI FILHO, A.; BARNI, N.A.; MALUF, J.R.T.; RADIN, B.; ANJOS, C.S. Época de semeadura para milho e soja visando à redução de risco por deficiência hídrica, no Rio Grande do Sul. Revista Brasileira de Agrometeorologia, Santa Maria, v.13, n.2, p.191-200, 2005.

MELHORANÇA, A.L.; MESQUITA, A.N. Efeito do espaçamento e épocas de semeadura sobre o rendimento e características agronômicas da soja em Dourados, MS. Pesquisa Agropecuária Brasileira, Brasília, v.17, n.5, p.729-732, 1982.

MINUZZI, A.; RANGEL, M.A.S.; BRACCINI, A. de L.; SCAPIM, C.A.; MORA, F.; ROBAINA, A.D.

Rendimento, teores de óleo e proteínas de quatro cultivares de soja, produzidas em dois locais no Estado do Mato Grosso do Sul. Ciência e Agrotecnologia, Lavras, v.33, n.4, p.1047-1054, 2009.

MOTTA, I.S.; BRACCINI, A.L.; SCAPIM, C.A.; GONÇALVES, A.C.A.; BRACCINI, M.C.L.

Características agronômicas e componentes da produção de sementes de soja em diferentes épocas de semeadura. Revista Brasileira de Sementes, Brasília, v.22, n.2, p.153-162, 2000. 
MOTTA, I.S.; BRACCINI, A.L.; SCAPIM, C.A.; INOUE M.H.; ÁVILA, M.R.; BRACCINI, M.C.L.Época de semeadura em cinco cultivares de soja: I., efeito nas características agronômicas. Acta Scientiarum Agronomy, Maringá, v.24, n.5, p.1275-1280, 2002.

NAKAGAWA, J.; ROSOLEM, C.A.; MACHADO, J.R. Épocas de semeadura da soja: I., efeitos na produção de grãos e nos componentes da produção. Pesquisa Agropecuária Brasileira, Brasília, v.18, n.11, p.1187-1198, 1983.

PEIXOTO, C.P.; CÂMARA, G.M.S.; MARTINS, M.C.; MARCHIORI, L.F.S.; GUERZONI, R.A.; MATTIAZZI, P.
Sowing date and plant density of soybean: I., yield components and grain yield. Scientia Agricola, Piracicaba, v.57, n.1, p.153-162, 2000.

PELÚZIO, J.M.; FIDELIS, R.R.; ALMEIDA JÚNIOR, D.; BARBOSA, V.S.; RICHTER, L.H.M.; SILVA, R.R. da; AFFÉRRI, F.S. desempenho de cultivares de soja, em duas épocas de semeadura, no sul do estado do Tocantins. Bioscience Journal, Uberlândia, v.22, n.2, p.69-74, 2006.

RAMALHO, M.A.P.; FERREIRA, D.F.; OLIVEIRA, A.C. A experimentação em genética e melhoramento de plantas. Lavras: UFLA, 2000. 134p. 